\title{
Fechado no presente
}

\author{
Rui Aires Augusto
}

\author{
João Tuna, Dorme devagar, in AA.VV., Dramaturgias \\ emergentes, Porto Et Lisboa, Cotovia, Cadernos Dramat, \\ n. ${ }^{\circ}$ 5, Vol. 1, 2001, pp.163-192.
}

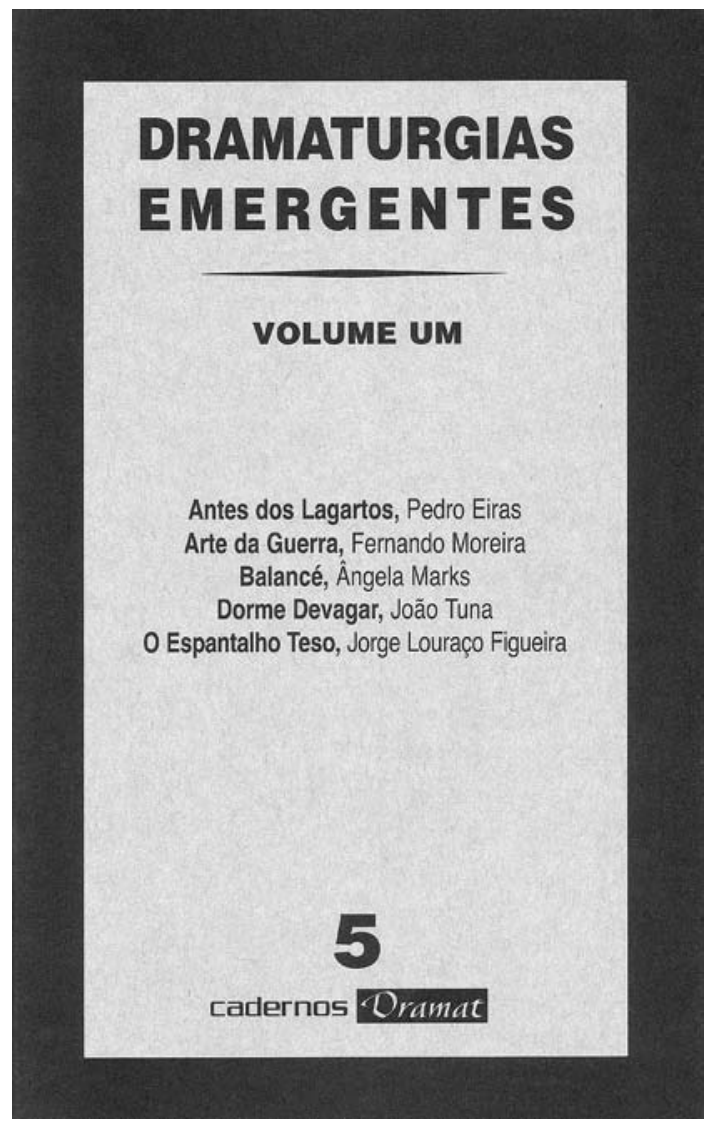

A peça Dorme devagar de João Tuna foi levada à cena num espectáculo com o mesmo nome apresentado pela ASSéDIO (Associação de Ideias Obscuras) no âmbito da $3^{\text {a }}$ edição do Festival PoNTI. Entre 26 de Junho e 3 de Julho de 2001, sob a orientação de Nicolau Pais - co-adjuvado por Rosa Quiroga -, João Pedro Vaz (Vitor) e Rute Pimenta (Ana) puderam evoluir nas "tábuas" do Balleteatro Auditório no Porto.'

A produção desse espectáculo foi o culminar de uma iniciativa do agora suspenso DRAMAT - Centro de Dramaturgias Contemporâneas, do Teatro Nacional São João, que em 1999 deu início a uma oficina de escrita teatral destinada a um pequeno grupo de autores iniciantes, poucos deles com peças encenadas e/ou publicadas, que pudessem cumprir o programa de definição da dramaturgia portuguesa, preparando-os ainda para a realidade teatral que se caracteriza por ser um trabalho conjunto, de contaminações, de participação, desígnio de uma arte colectiva.

0 autor, estando ligado ao teatro por exercer uma actividade que se pode considerar paralela ao evento (fotografia de cena), contribuiu pela primeira vez com um texto dramático. A sua contribuição criativa em outra arte visual (o cinema) será mais profícua e diversificada, sendo de assinalar, no domínio da escrita, a autoria dos argumentos de Apartamento (1997), Primavera (1997), António Lagarto - Percursos (2000).

0 interesse em recensear o texto de João Tuna, como agente da dita "dramaturgia emergente", reside na confrontação entre a manutenção de formas atestadas da escrita teatral e a possibilidade de reinvenção dessas formas, sobretudo pela constatação da situação conflitual paradigmática do huis clos contra a tendência para a diluição do conflito no drama moderno. ${ }^{2}$ dando conta sobretudo do aspecto do conflito dramático, apresento em poucas palavras o resumo da sua fábula.

Na iminência de um terramoto que irá devastar Lisboa a uma hora prevista pela Prevenção Civil (talvez uma réplica do ocorrido em 1755), um casal de professores (Ana e Vitor) com uma relação amorosa mal definida decide refugiar-se na cave do seu prédio (e o texto não é explícito neste ponto, não deixando entrever se afinal vivem juntos). Este encerramento preparado, que toma toda a forma de huis clos, é o ponto de partida para as duas personagens dirimirem as suas divergências. Entre ciúmes, sentimentos de insegurança (sobretudo da personagem masculina) e sobejas diferenças, a situação-limite provoca o afastamento do casal, esgotada toda a margem de confiança, rematando a acção com o anúncio do fim da relação e com uma revelação talvez ambígua de um elemento que iria elidir o fosso que os separa - anúncio ou suposição da gravidez de Ana.

A acção acima resumida conforma-se à extensão de um acto. Ainda que o autor não tenha praticado essa intervenção exterior, somos capazes de assegurar essa orientação, pelo que o texto, concentrando a sua matéria dramática sobre uma crise, está unido pela continuidade de um tema até ao seu fim, jogado de um só trecho.

E se o autor se escusa a intervir no aspecto formal, percebemos contudo a sua tentativa de definição do drama logo em paratexto. A apresentação das personagens é tendenciosa, ou indutora, e de imediato introduz o leitor
Antes, porém, de iniciar a análise do texto de João Tuna,
${ }^{1}$ Para a informação completa da ficha técnica deste espectáculo,

consulte-se, na entrada "Dorme Devagar", a CETBase - base de dados de espectáculos teatrais em Portugal do Centro de Estudos de Teatro da Universidade de Lisboa (www.fl.ul.pt/centro-estudos-teatro.htm).

${ }^{2}$ Esta última questão faz parte das minhas

cogitações de momento, a serem desenvolvidas numa tese, como um dos

aspectos a considerar para a perspectiva de uma poética (possivel?) da dramaturgia portuguesa contemporânea. 
na situação conflitual (neste caso o espectador tão-pouco usufrui dessa informação). Digo tendenciosa e indutora porque desmascara à partida o carácter das personagens e o próprio gesto da sua construção, ao mesmo tempo que esses sinais servem sobretudo para justificar a matriz conflitual, para "contextualizar" o conflito: Ana é bonita; Vitor não é muito bonito e é irónico; são ambos professores de artes, o que justificará, em parte, os objectos em presença.

Esses objectos não são apenas decorativos: eles servem para serem usados em favor do avanço da situação conflitual e do seu clímax, servem para introduzir dados novos, são objectos significantes.

Podem ser objectos pessoais que definam a condição das personagens: cavaletes e telas de professor de Educação Visual/artista plástico, violino de professora de

Música/violinista. São ainda objectos que potenciam a crise entre personagens, ou que incitam a desconfiança no outro: as telas inacabadas são sinal de indefinição dos afectos, que levam à crise de insegurança do outro; assim como é uma suspensão dos afectos o acto dispersivo de tocar violino que convoca um sentimento de indiferença e uma interrupção na ligação a dois.

Esses mesmos objectos, que definem a condição das personagens, em última instância são a sua marca na apropriação de um espaço que não é o seu e que não é um espaço de convivência e de circulação. A estes juntam-se os objectos impessoais de sobrevivência.
Pela especificidade presente do espaço, há objectos vazios de sentido porque uma vez dentro dele (do espaço), este convoca o estranhamento do seu uso pela impossibilidade de comunicação, de intercâmbio com o exterior. É o caso do telemóvel e do rádio, objectos significantes pelo que atestam do cerramento da cena. Outros há que partilham das características de fechamento e desuso do espaço, como a lâmpada, "caixas de cartão", outras telas, uma cadeira velha.

Se fechamento e desuso é o que caracteriza o espaço, esse facto justifica-se pela iminência com que obriga à sua apropriação e pela necessidade da sua improvisação para o jogo, para o dirimir dos conflitos. Como espaço desusado, inóspito, é forçoso que se crie uma situação mais ou menos imprevista (mas em parte preparada), que leve a que seja habitado. $E_{1}$ ainda fundamental ao huis clos, já que não há saida possivel e porque as personagens se vêem cercadas, a tensão assoma e potencia os conflitos, espicaça as personagens a jogar, a fazer valer os seus princípios, a pôr em causa os princípios do outro, a relevar as divergências, as diferenças.

Este não é propriamente um espaço doméstico que exacerbe a crise - a tendência aventada por Jean-Pierre Sarrazac no drama moderno desde Tchekov seria realizar o espaço doméstico como lugar desarmonioso, catalisador dos conflitos. Ainda assim é um espaço interior, fechado, e o desequilibrio/desordem que convoca advém sobretudo da
Dorme devagar, enc. Nicolau Pais, Assédio/TNSJ, Balleteatro Auditório, Porto, 2001 (Rute Pimenta e João Pedro Vaz), fot. João Tuna.

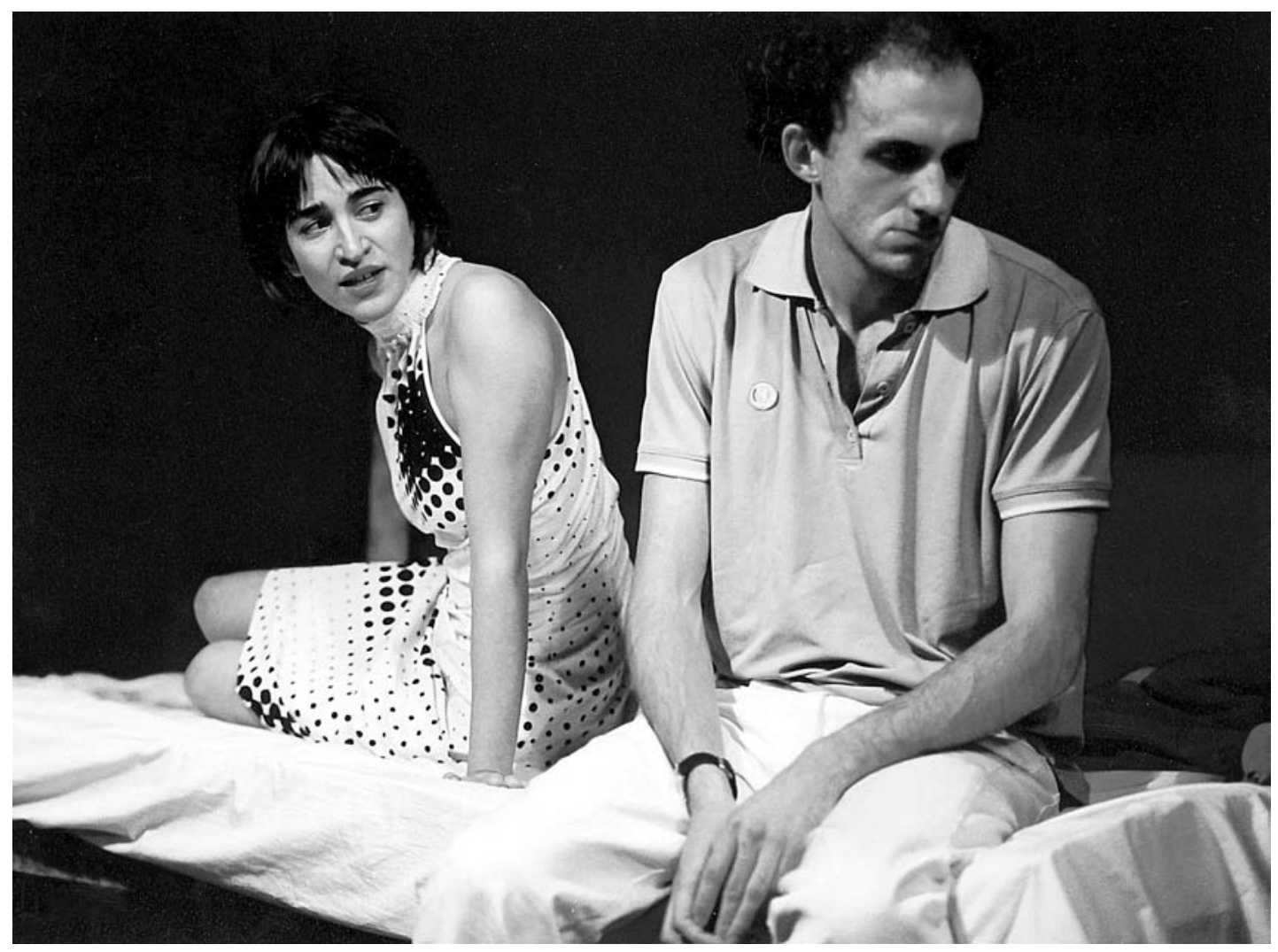


improbabilidade de ser ocupado, da necessidade de o habitar pressentindo-o, mais do que como um refúgio - como um sepulcro, o lugar do fim.

No meio da cena, variação da mesa de Sarrazac como altar sacrificial plural, a cama como altar dual, não de duas personagens, mas de dois sentidos do conflito, jogado em parceria com um vestido provocador. As personagens flutuam na ambiguidade dos seus afectos, colocando de cada lado desse altar, ora o sono conciliador, ora o sexo dispersivo, na impossibilidade de uma fórmula congregadora - 0 amor. Símbolo máximo da crise doméstica (esta, pelo menos), a cama não é aí um altar de adoração, mas a expressão do dissídio.

A situação conflitual parece resultar dessa separação, que por sua vez convoca a indefinição, a insegurança, a suspeita, a não comunicação, que numa situação de tumulto dá lugar à instabilidade e à crise. E é por picos de crise que a acção avança, como réplicas do terramoto, jogadas por uma personagem à vez. Estes picos de crise são intervalados por momentos de conciliação, mas o seu crescendo não permite outro fim que não seja a ruptura como resolução do conflito.

Como forma acabada do huis clos, surge o momento de dispersão final e o regresso à ordem. 0 espaço exterior é um espaço libertador, onde se dispersa a claustrofobia. A conciliação com o espectador é essa oportunidade de finalmente poder respirar e deixar de servir de árbitro de pingue-pongue das nevroses individuais e relacionais

Num texto programático de Fernando Mora Ramos, então coordenador do DRAMAT, faz-se valer que se entende por dramaturgia contemporânea "aquele conjunto de obras e autores que romperam com a tradição da peça bem feita e que abriram caminho para dramaturgias capazes de revelar e conter aspectos da vida contemporânea".

Embora dificilmente possa ser definida uma "poética" do presente para o texto dramático, as pistas lançadas por Jean-Pierre Sarrazac em 0 futuro do drama dão base para questionar essa fácil assunção de contemporaneidade que se quer colar ao texto de João Tuna.

A metodologia de trabalho assumida no clima da oficina de escrita do DRAMAT garante a preocupação da presença da cena na construção do texto. Mas não concordo que, para assegurar o seu carácter emergente, baste apresentar uma suposta actualidade dos temas e dos signos em presença sob uma forma mais ou menos fixa e, do mesmo modo, convencional. Arrisco até em considerar inútil a formulação do encenador Nicolau Pais que proclama ser emergente uma tendência geracional que coloca "descomplexadamente os afectos em primeiro lugar".

Prefiro considerar emergente a preocupação com os elementos estruturais e com a (re)criação de formas em detrimento da actualidade dos temas atestada por relatos mascarados de conversas em linguagem coloquial, quotidiana, registos da sociedade actual. Não basta isso. Emergente seria o movimento/gesto de romper com a conservação das formas legadas pela tradição, seria assumir a crise da unidade da acção fragmentando a fábula pela simultaneidade, pela repetição, pela variação, dispersando o tema unificador e o desenrolar seguro da acção. Emergente seria convocar o hibridismo, em que os elementos narrativos convivem com os elementos dramáticos, e até mesmo chamar à liça o modo lírico; seria promover a descontinuidade que fizesse disparar o drama para lá do seu microcosmo preso à necessidade dinâmica do conflito; seria ferir os princípios do diálogo dramático.

Contento-me em perceber no texto de João Tuna a problematização do espaço interior, não propriamente doméstico, como lugar desarmonioso que convoca os conflitos. No entanto, a problematização do espaço interior é feita de forma mais ou menos conservadora. 0 fechamento desse espaço é hermético, diz respeito apenas às personagens, não abre brechas para o questionamento e para a intrusão do exterior.

Dorme Devagaré um texto equilibrado, seguro, sem grandes sobressaltos ou consideráveis inovações, que responde bem à ideia de peça bem feita - isto é, a um tipo de dramaturgia pós-aristotélica que conserva a estrutura fechada no drama, que se caracteriza pelo avanço continuado, exclusivo (no sentido de fechado em si) e progressivo da acção, cuja curva apresenta altos e baixos, picos (ou beats) proporcionados por uma lógica de causa>efeito. Poderia até ser dito que aposta na ilusão naturalista, como peça bem feita, confiando para a sua recepção na identificação e na verosimilhança. Questiona-se, então, se o texto de João Tuna será emergente por ser novíssimo ou se, aliado a isso, aponta, não já para o presente porque "quem quer ser do seu tempo já está ultrapassado", mas para o futuro.

\section{Referência bibliográfica}

SARRAZAC, Jean-Pierre, 0 futuro do drama: Escritas dramáticas contemporâneas, trad. Alexandra Moreira da Silva, Porto, Campo das Letras, Cadernos Dramat, n. 9, 2002. 